\title{
Effect of body position on gas exchange after thoracotomy
}

\author{
DOUGLAS SEATON, ${ }^{1} \mathrm{~N}$ L LAPP, AND W K C MORGAN \\ From the Division of Pulmonary Diseases, West Virginia University, Morgantown, WVa, USA
}

ABSTRACT To determine the effect of change in body position on gas exchange after thoracotomy, 12 patients with potentially resectable lung tumours were studied before and 24 hours after operation. Measurements of arterial blood gas tension $\left(\mathrm{PaO}_{2}, \mathrm{PaCO}_{2}\right)$, alveolar-arterial oxygen difference $\left(\mathrm{A}-\mathrm{adO}_{2}\right)$, venous admixture effect (Qs/Qt percent), and physiological dead space to tidal volume ratio $(\mathrm{Vd} / \mathrm{Vt})$, were made in the supine, and left and right lateral decubitus positions. Preoperatively, altering position did not affect gas exchange significantly. After thoracotomy in the lateral position with the unoperated side dependent, $\mathrm{PaO}_{2}$ was significantly higher, and $\mathrm{A}-\mathrm{adO}_{2}$ and Qs/Qt percent significantly lower than in the supine position. Postoperatively, the lateral position with the side of thoracotomy dependent was usually associated with the worst gas exchange. Only three patients achieved their best postoperative gas exchange in this position. In two this may have resulted from dependent small airway closure during tidal breathing, due to airways obstruction and old age, and in the third from postoperative atelectasis in the unoperated lung. No significant changes in mean $\mathrm{PaCO}_{2}, \mathrm{Vd} / \mathrm{Vt}$, or minute ventilation ( $\mathrm{VE}$ ) occurred with different positioning.

Early bronchospirometric studies in lateral positions suggested that the upper lung had a higher ventilation to perfusion $(\dot{\mathrm{V}} / \mathbf{Q})$ ratio than the lower (Vaccarezza et al, 1943; Inada et al, 1954). Bryan et al (1964) confirmed the presence of $\dot{V} / \dot{Q}$ gradients with ${ }^{133}$ xenon, showing that they increased in a vertical direction irrespective of the posture chosen. Kaneko et al (1966) confirmed these findings in normal subjects in different decubitus postures, concluding that a better total match of ventilation and perfusion occurred in these positions than in upright postures. Zack et al (1974) examined the effect of body position on $\mathrm{PaO}_{2}$ in 13 patients with predominantly unilateral lung disease, and they observed that the lateral position in which the diseased lung was dependent produced a significantly lower $\mathrm{PaO}_{2}$ than the opposite position.

We wished to investigate whether the position in which patients were nursed after thoracotomy would influence gas exchange and hence postoperative management.

\section{Methods}

Twelve consecutive referrals who had potentially resectable lung tumours were studied (table 1). None

'Present address: Ipswich Hospital, Heath Road Wing, Ipswich IP4 5PD. had preoperative radiographic evidence of asymmetrical lung disease, other than tumour. All were cigarette smokers and had chronic bronchitis (MRC, 1966). Five had moderate airways obstruction (Gaensler and Wright, 1966).

One hour before operation each subject rested for 15 minutes in three successive positions: supine, and left and right lateral decubitus, the order being randomised. They breathed room air through an of open circuit consisting of a mouth-piece, two-way $₹$ valve (Collins, P320), and connections so that $\mathrm{O}$ expired gas could be collected in a balloon during the last three minutes in each position. During the last 20 seconds of gas collection, arterial blood was obtained with a glass syringe through a radial artery o cannula. During anaesthesia a Swan-Ganz catheter $N$ (Edwards, 93-117-5F) was placed in the main $\underset{\mathrm{N}}{ }$ pulmonary artery trunk, to allow postoperative mixed venous sampling.

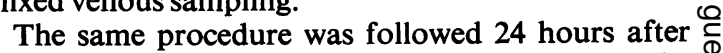
operation during spontaneous breathing, after the $\stackrel{\odot}{?}$ following criteria had been observed: $(a)$ that the open circuit delivery system was connected to a $\overrightarrow{0}^{\circ}$ Venturi device, which provided an inspired $\mathrm{O}_{2} \stackrel{\vec{D}}{\mathrm{D}}$ concentration (FIo F $_{2}$ of $0.40 \pm 0.02 ;(b)$ that the supine $\frac{}{\mathbb{D}}$ $\mathrm{PaO}_{2}$ had been stable on an FIO2 of 0.4 during the $\frac{\varrho}{\sigma}$ hour preceding measurements; and (c) that the pulmonary artery cannula was correctly positioned. 
Table 1 Details of 12 consecutive referrals who had potentially resectable lung tumours

\begin{tabular}{lllccll}
\hline Patient & Age & Sex & FVC\% pred & FEV $\%$ pred & FEV $/ F V C \%$ & Operative procedure \\
\hline 1 & 52 & M & 76 & 74 & 72 & Left lower lobectomy \\
2 & 58 & F & 120 & 81 & 51 & Left upper lobectomy \\
3 & 59 & F & 80 & 78 & 72 & Left “open and shut" thoracotomy \\
4 & 63 & M & 112 & 106 & 66 & Right upper lobectomy \\
5 & 45 & F & 74 & 64 & 67 & Left lower lobectomy \\
6 & 70 & M & 88 & 56 & 46 & Right upper lobectomy \\
7 & 56 & F & 93 & 83 & 67 & Right upper lobectomy \\
8 & 56 & M & 94 & 59 & 42 & Right lower lobectomy \\
9 & 58 & F & 99 & 98 & 74 & Right upper lobectomy \\
10 & 48 & F & 80 & 85 & 82 & Right upper lobectomy \\
11 & 64 & M & 72 & 56 & 54 & Left lower lobectomy \\
12 & 53 & F & 106 & 74 & 53 & Right lower lobectomy \\
Mean & 56.83 & (5M) & $91 \cdot 16$ & 76.18 & $62 \cdot 17$ & \\
SD & 6.93 & (7F) & $15 \cdot 70$ & 15.91 & 12.55 & \\
\hline
\end{tabular}

Arterial and mixed venous samples were taken simultaneously during gas collection. No additional analgesia was required during the manoeuvres.

Duplicate measurements of $\mathrm{PaO}_{2}$ and $\mathrm{PaCO}_{2}$ were obtained using a blood gas analyser (Instrumentation Lab, 113-04). Expired gas was analysed using an infrared $\mathrm{CO}_{2}$ analyser (Beckman, LB-2) and a polarographic $\mathrm{O}_{2}$ analyser (Beckman, OM-11). VE (STPD) was obtained by emptying the balloon into a Tissot spirometer. Haemoglobin was measured preand post-operatively. $\mathrm{A}-\mathrm{adO}_{2}$ was calculated using the ideal alveolar air equation (Riley and Cournand, 1948/49). Qs/Qt was calculated using the equation:

$$
\dot{Q} \mathrm{~s} / \mathrm{Qt}=\frac{\mathrm{CĆO}_{2}-\mathrm{CaO}_{2}}{\mathrm{CĆO}_{2}-\mathrm{CVNO}_{2}}
$$

where $\mathrm{Cc}_{2}=$ end capillary $\mathrm{O}_{2}$ content, $\mathrm{CaO}_{2}=$ arterial $\mathrm{O}_{2}$ content, and $\mathrm{CV}_{\mathrm{V}} \mathrm{O}_{2}=$ mixed venous $\mathrm{O}_{2}$ content. $\mathrm{O}_{2}$ content was estimated using the measured oxygen tensions, the haemoglobin concentration, the oxyhaemoglobin dissociation curve, correction for $\mathrm{pH}$ (Severinghaus, 1958), and the solubility of $\mathrm{O}_{2}$ in the blood (Sendroy et al, 1934). It was assumed that $\mathrm{Pco}_{2}$ equalled $\mathrm{PAO}_{2}-1 \mathrm{mmHg}$, and that the preoperative arteriovenous $\mathrm{O}_{2}$ content difference was $4.5 \mathrm{ml} / 100 \mathrm{ml}$. Vd/Vt was calculated using Bohr's equation.

\section{Results}

Table 2 shows the effect of pre- and post-operative change on mean $\mathrm{PaO}_{2}, \mathrm{PaCO}_{2}, \mathbf{Q} / \mathbf{Q} \mathrm{t}$ percent, and $\mathrm{Vd} / \mathrm{Vt}$.

Effect of preoperative change in body position-No consistent changes in mean values occurred between any of the three positions. Intra-subject variations occurred in random fashion irrespective of the

Table 2 Gas exchange pre-and post-operatively

\begin{tabular}{|c|c|c|c|c|c|c|}
\hline \multirow{2}{*}{$\begin{array}{l}\text { Mean } \\
\text { (SD in parentheses) }\end{array}$} & \multicolumn{3}{|c|}{$\begin{array}{l}\text { Preoperative } \\
\mathrm{FIO}_{2}: 0 \cdot 21\end{array}$} & \multicolumn{3}{|c|}{$\begin{array}{l}\text { Postoperative } \\
\mathrm{FIO}_{2}: 0 \cdot 40\end{array}$} \\
\hline & & $S$ & $U$ & $D$ & $S$ & $U$ \\
\hline $\mathrm{PaO}_{2}$ & $\begin{array}{l}69 \cdot 01 \\
(5 \cdot 18)\end{array}$ & $\begin{array}{l}68 \cdot 92 \\
(4 \cdot 24)\end{array}$ & $\begin{array}{l}67 \cdot 98 \\
(3 \cdot 96)\end{array}$ & $\begin{array}{r}105 \cdot 56^{*} \\
(5 \cdot 50)\end{array}$ & $\begin{array}{c}100 \cdot 42^{*} \\
(13 \cdot 89)\end{array}$ & $\begin{array}{c}97 \cdot 68 \\
(15 \cdot 07)\end{array}$ \\
\hline $\mathrm{PaCO}_{2}$ & $\begin{array}{l}35 \cdot 79 \\
(2 \cdot 58)\end{array}$ & $\begin{array}{l}35 \cdot 65 \\
(1 \cdot 21)\end{array}$ & $\begin{array}{l}35 \cdot 93 \\
(2 \cdot 28)\end{array}$ & $\begin{array}{l}40 \cdot 05 \\
(2 \cdot 83)\end{array}$ & $\begin{array}{l}38 \cdot 76 \\
(2 \cdot 83)\end{array}$ & $\begin{array}{l}39 \cdot 54 \\
(1 \cdot 88)\end{array}$ \\
\hline$A-\mathrm{adO}_{2}$ & $\begin{array}{l}30 \cdot 38 \\
(5 \cdot 71)\end{array}$ & $\begin{array}{l}30 \cdot 92 \\
(3 \cdot 03)\end{array}$ & $\begin{array}{l}30.92 \\
(5 \cdot 96)\end{array}$ & $\begin{array}{c}120 \cdot 58 * \\
(6 \cdot 58)\end{array}$ & $\begin{array}{l}127 \cdot 07^{*} \\
(14 \cdot 69)\end{array}$ & $\begin{array}{l}129 \cdot 41 \\
(15 \cdot 87)\end{array}$ \\
\hline Q́s/Q't \% & $\begin{array}{l}12 \cdot 19 \\
(3 \cdot 26)\end{array}$ & $\begin{array}{l}12 \cdot 15 \\
(2 \cdot 34)\end{array}$ & $\begin{array}{l}12 \cdot 57 \\
(2 \cdot 87)\end{array}$ & $\begin{array}{c}7 \cdot 57^{*} \\
(2 \cdot 08)\end{array}$ & $\begin{array}{c}8 \cdot 91^{*} \\
(3 \cdot 47)\end{array}$ & $\begin{array}{c}9.58 \\
(4 \cdot 50)\end{array}$ \\
\hline $\mathrm{Vd} / \mathrm{Vt}$ & $\begin{array}{c}0.34 \\
(0.06)\end{array}$ & $\begin{array}{c}0.33 \\
(0.05)\end{array}$ & $\begin{array}{c}0.34 \\
(0.08)\end{array}$ & $\begin{array}{c}0.51 \\
(0.04)\end{array}$ & $\begin{array}{c}0.49 \\
(0.04)\end{array}$ & $\begin{array}{c}0.50 \\
(0.03)\end{array}$ \\
\hline
\end{tabular}

Where S: supine, D: lateral decubitus with tumour-free or unoperated lung dependent, U: lateral decubitus with tumour-free or unoperated lung uppermost.

* = Mean difference D-S statistically significant.

$\left(\mathrm{PaO}_{2}, \mathrm{PaCO}_{2}\right.$ and $\mathrm{A}-\mathrm{adO}_{2}$ are given in $\mathrm{mmHg}$. Conversion factor: $\left.1 \mathrm{mmHg}=7 \cdot 5 \mathrm{kPa}\right)$. 
position of the tumour-bearing lung in relation to the opposite lung. No significant change in VE occurred between preoperative positions.

Effect of postoperative change in body position-In the lateral position with the unoperated side dependent (D) $\mathrm{PaO}_{2}$ was significantly higher $(\mathrm{P}<0.01)$, and $\mathrm{A}-\mathrm{adO}_{2}$ and $\mathrm{Q} / \mathrm{Q}$ t percent were significantly lower $(\mathrm{P}<0.01$ and $\mathrm{P}<0.05$ respectively) than in the supine position (S). Comparing unoperated side dependent (D) with unoperated side uppermost (U), the mean results did not differ significantly because in three subjects gas exchange improved rather than worsened with the thoracotomy dependent. $\mathrm{Vd} / \mathrm{Vt}, \mathrm{PaCO}_{2}$, and $\dot{V} E$ showed no significant change with postoperative positioning.

Comparison of pre-and post-operative values-While breathing an $\mathrm{FIO}_{2}$ of $0 \cdot 4, \mathrm{PaO}_{2}$ fell in only one subject (9), who also had the highest postoperative Qs/Qt percent. Mean $\mathrm{PaCO}_{2}$ values for each position postoperatively were significantly higher than the preoperative values for the corresponding postures $(\mathrm{P}<0.05$ for each position). Mean $\mathrm{Vd} / \mathrm{Vt}$ also increased for each postoperative posture $(\mathrm{P}<0.001$ for all positions). $\mathrm{A}-\mathrm{adO}_{2}$ was increased postoperatively ( $\mathrm{P}<0.001$ for all positions). As expected Qs/Qt percent postoperatively was lower on $40 \%$ oxygen. This fall was only significant for the lateral position with the tumour-free/unopened hemithorax dependent $(P<0.05)$. $\dot{V} E$ for each preoperative posture ranged between 5.30 and 5.50 1 and increased significantly postoperatively, to between 6.43 and $6.841(\mathrm{P}<0.001$ for lateral and $<0.02$ for supine postures).

\section{Discussion}

Preoperatively our subjects did not behave differently from young controls (Zack et al, 1974), in that gas exchange was not influenced by change in decubitus posture. There are no published data of this nature for older controls.

The postoperative finding of improved gas exchange in the lateral position with the unopened hemithorax dependent, compared with the supine posture, implies (in the absence of a change in $\mathrm{PaCO}_{2}$ or $\dot{V} E$ between positions) that the former posture resulted in better overall matching of ventilation and perfusion in the lungs.

Apart from having reduced surface area of lung available for gas exchange as a result of resection, possibly in our postoperative supine patients the side on which the operation had been performed was relatively hypoventilated as a result of areas of incomplete postoperative lung re-expansion, or of splinting of the affected hemithorax because of pain. Were this the case an abnormally high venous admixture effect would apply to that lung, assuming that pulmonary arterial perfusion to remaining lung 음 tissue was little changed. If such a patient was then $\frac{\bar{D}}{\bar{D}}$ placed in a lateral position, thoracotomy uppermost, $\stackrel{\mathbb{Q}}{\varrho}$ perfusion to this poorly ventilated lung would be reduced as an effect of gravity (West and Dollery, 1960 ), and this in turn would reduce the venous $\vec{\circ}$ admixture occurring in the uppermost lung. Such $\overrightarrow{\vec{\omega}}$ a positional change might also further augment the $\stackrel{\sigma}{\omega}$ efficiency of gas exchange in that patient, by placing $\vec{x}$ as large a volume of "good lung"-that is lung that $\dot{\omega}$

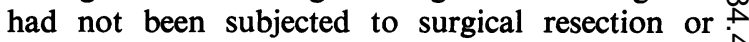
handling -in the dependent position, in which if ventilation and perfusion are normally better $\vec{\infty}$ matched (Kaneko et al, 1966). If this hypothesis is 을 correct it would account for our observation of $\rightarrow$ significantly increased $\mathrm{PaO}_{2}$ and significantly reduced $\longrightarrow$ $\mathrm{A}^{-\mathrm{adO}_{2}}$ and $\mathbf{Q} / \mathbf{Q} \mathrm{t}$ percent in the lateral decubitus position with the unoperated side dependent.

The relationship of gas exchange to position in these subjects may also have been influenced by small airway closure during tidal breathing. All of our subjects were smokers, and this is associated with raised closing volume (McCarthy et al, 1972). Closing volume also increases linearly with age $\overline{0}$ (LeBlanc et al, 1970), and as functional residual capacity (FRC) falls when a seated subject becomes $\stackrel{\mathbb{Q}}{\square}$ supine, it has been estimated that in normal supine $\overrightarrow{\overrightarrow{0}}$ subjects airway closure occurs during tidal breathing 3 by the age of 44 years (LeBlanc et al, 1970). No regression equations for closing volume against age for subjects in the lateral decubitus postures have been published. It has, however, been shown that a 응 fall in FRC from the seated to either lateral decubitus $\underset{x}{x}$ position is only about half as great as that from the sitting to supine positions (Blair and Hickam, 1955). Accordingly, small airway closure per unit lung volume in our patients was probably less in the lateral than in the supine positions, and this may have $\frac{\text { ? }}{3}$ contributed to the improvement in gas exchange on $\rightarrow$ changing from the supine position to lateral decubitus with unoperated side dependent. Presumably any $N$ potential benefit from turning to the opposite decubitus position was outweighed by the factors $\tilde{O}$ stated in the preceding paragraph.

Three subjects (6-8) had better gas exchange in the lateral decubitus posture with the operated-upon 0 hemithorax dependent. In one (7) the postoperative chest radiograph showed shadowing consistent with $\stackrel{\infty}{+}$ areas of atelectasis in the left lower lobe on the $T$ unoperated side. The degree of $\dot{V} / Q$ mismatching in $\stackrel{\vec{D}}{\vec{D}}$ this atelectatic, dependent left lung was probably $\stackrel{\mathbb{D}}{\stackrel{D}{~}}$ therefore greater than that occurring in the surgically $\stackrel{\mathbb{Q}}{\Omega}$ manipulated but radiographically fully expanded right lung when it was dependent. The other two subjects who behaved paradoxically had more severe 
airways obstruction than the remainder, and possibly their diseased dependent airways closed at a higher volume on expiration, so that during tidal breathing the number of small airways closing per unit volume of dependent lung exceeded that of the other patients. Were the closing volumes of these subjects sufficiently large, then the potential of the unoperated lung as a better gas exchanger would be wasted, by placing it in the more dependent position. This explanation would be particularly applicable to one subject (6) who as the oldest member of the group would, on the criterion of age alone, have the highest closing volume.

A comparison of measurements between the same position pre- and post-operatively shows that despite increased $\dot{\mathrm{VE}}$ after surgery, $\mathrm{PaCO}_{2}$ rose indicating overall alveolar hypoventilation. The observed increased $\mathrm{Vd} / \mathrm{Vt}$ is also consistent with less efficient $\mathrm{CO}_{2}$ clearance. An increase in $\mathrm{A}_{-}-\mathrm{adO}_{2}$ is a normal consequence of raising $\mathrm{FIo}_{2}$; however, Cole and Bishop (1963) in a group of normal subjects of comparable age to our subjects, obtained a smaller mean increase in $\mathrm{A}-\mathrm{adO}_{2}$ for a greater increase in $\mathrm{FIo}_{2}$, suggesting that the increased $\mathrm{A}-\mathrm{adO}_{2}$ in our patients was consistent with worsened postoperative gas exchange, and not entirely explainable by the change in $\mathrm{FIO}_{2}$ alone. The reduction of mean $\mathbf{Q} / \mathbf{Q} t$ percent observed postoperatively is a consequence of increased $\mathrm{FIO}_{2}$, and does not indicate a reduced physiological shunt. Breathing $100 \%$ oxygen has been shown to produce increased perfusion of dependent lung in the lateral decubitus position in normal subjects (Arborelius et al, 1974), but it is uncertain to what extent $40 \%$ oxygen would alter $\dot{V} / Q$ relations in the positions studied by us.

The findings of this study clearly have a bearing on the postoperative management of subjects who have undergone thoracotomy. For the most part the results are in accord with what one might predict from previous investigations, carried out in normal subjects, in which regional ventilation and perfusion have been shown to be influenced by body position. Our study shows that the effects of changes in position on gas exchange in post-thoracotomy subjects were generally of limited magnitude except in one subject (3) whose $\mathrm{PaO}_{2}$ fell $35 \mathrm{~mm}$ when the operated side was in the dependent position. Were this patient to have had his blood gases analysed before and after he had been turned, such a change might well have been assumed to represent a grave deterioration in his condition. In three instances, however, change of position produced an anomalous and unexpected effect on gas exchange, though in general an adequate explanation for the anomaly was present. We conclude that in the management of subjects who have undergone thoracotomy, consideration should be given to the effects of position on pulmonary gas exchange, which in the absence of evidence to the contrary is usually better when the "good" lung is dependent.

This work was in part supported by a grant from the Wellcome Trust. We are grateful to the patients concerned for consenting to be studied, and also to the thoracic surgeons and anaesthetists of West Virginia University Hospital for their co-operation.

\section{References}

Arborelius, M, Granqvist, U, Lilja, B, and Zanner, C W (1974). Regional lung function and central haemodynamics in the right lateral body position during hypoxia and hyperoxia. Respiration, 31, 193-200.

Blair, E, and Hickam, J B (1955). The effect of change in body position on lung volume and intrapulmonary gas mixing in normal subjects. Journal of Clinical Investigation, 34, 383-389.

Bryan, A C, Bentivoglio, L G, Beerel, F, MacLeish, H, Zidulka, A, and Bates, D V (1964). Factors affecting regional distribution of ventilation and perfusion in the lung. Journal of Applied Physiology, 19, 395-402.

Cole, R B, and Bishop, J M (1963). Effect of varying inspired $\mathrm{O}_{2}$ tension on alveolar-arterial $\mathrm{O}_{2}$ tension difference in man. Journal of Applied Physiology, 18, 1043-1048.

Gaensler, E A, and Wright, G W (1966). Evaluation of respiratory impairment. Archives of Environmental Health, 12, 146-189.

Inada, K, Kishimoto, S, Satô, A, and Watanabe, T (1954). Bronchospirometry with the Carlens double lumen catheter. Evaluation and exercise test.Journalof Thoracic Surgery, 27, 173-186.

Kaneko, K, Milic-Emili, J, Dolovich, M B, Dawson, A, and Bates, D V (1966). Regional distribution of ventilation and perfusion as a function of body position. Journal of Applied Physiology, 21, 767-777.

LeBlanc, P, Ruff, F, and Milic-Emili, J (1970). Effects of age and body position on "airway closure" in man. Journal of Applied Physiology, 28, 448-451.

McCarthy, D S, Spencer, R, Greene, R, Milic-Emili, J (1972). Measurement of "closing volume" as a simple and sensitive test for early detection of small airway disease. American Journal of Medicine, 52, 747-753.

Medical Research Council, Committee on Research into Chronic Bronchitis (1966). Questionnaire on Respiratory Symptoms. MRC, London.

Riley, R L, and Cournand, A (1948/49). "Ideal" alveolar air and the analysis of ventilation-perfusion relationships in thelungs. Journal of Applied Physiology, 1, 825-847.

Sendroy, J, Dillon, R T, and Van Slyke, D D (1934). Studies of gas and electrolyte equilibria in blood. Journal of Biological Chemistry, 105, 597-632.

Severinghaus, J W, (1958). Oxyhemoglobin dissociation curve correction for temperature and $\mathrm{pH}$ variation in human blood. Journal of Applied Physiology, 12, 485-486. 
Vaccarezza, R F, Bence, A, Lanari, A, Labourt, F, and Segura, R G (1943). The study of the two lungs separately in practical and research work. Diseases of the Chest, 9, 95-114.

West, J B, and Dollery, C T (1960). Distribution of blood flow ventilation-perfusion ratio in the lung, measured with radioactive $\mathrm{CO}_{2}$. Journal of Applied Physiology, 15, 405-410.
Zack, M B, Pontoppidan, H, and Kazemi, H (1974). The effect of lateral positions on gas exchange in pulmonary disease. American Review of Respiratory Disease, 110 , 49-55.

Requests for reprints to: Dr D Seaton, Ipswich Hospital, Heath Road Wing, Ipswich IP4 5PD. 